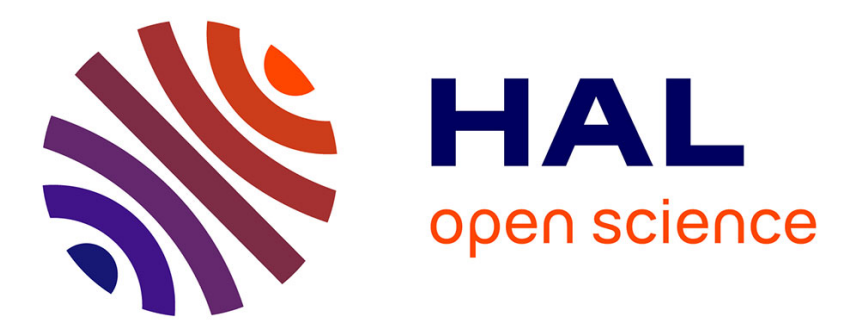

\title{
High-energy ball milling to enhance the reactivity of aluminum nanopowders
}

Bérangère André, Marie-Vanessa Coulet, Pierre-Henry Esposito, Benoit Rufino, R. Denoyel

\section{To cite this version:}

Bérangère André, Marie-Vanessa Coulet, Pierre-Henry Esposito, Benoit Rufino, R. Denoyel. Highenergy ball milling to enhance the reactivity of aluminum nanopowders. Materials Letters, 2013, 110, pp.108-110. 10.1016/j.matlet.2013.07.101 . hal-01504110

\section{HAL Id: hal-01504110 https://hal-amu.archives-ouvertes.fr/hal-01504110}

Submitted on 17 Nov 2017

HAL is a multi-disciplinary open access archive for the deposit and dissemination of scientific research documents, whether they are published or not. The documents may come from teaching and research institutions in France or abroad, or from public or private research centers.
L'archive ouverte pluridisciplinaire HAL, est destinée au dépôt et à la diffusion de documents scientifiques de niveau recherche, publiés ou non, émanant des établissements d'enseignement et de recherche français ou étrangers, des laboratoires publics ou privés. 


\title{
High-energy ball milling to enhance the reactivity of aluminum nanopowders
}

\author{
B. André ${ }^{a}$, M.-V. Coulet ${ }^{\text {a }}$, P.-H. Esposito ${ }^{a}$, B. Rufino ${ }^{\text {b }}$, R. Denoyel ${ }^{\text {b,* }}$ \\ a Aix-Marseille Université, CNRS, IM2NP UMR 7334, Campus de Saint Jérôme, 13397 Marseille Cedex 20, France \\ ${ }^{\mathrm{b}}$ Aix-Marseille Université, CNRS, MADIREL UMR 7246, Campus de Saint Jérôme, 13397 Marseille Cedex 20, France
}

\begin{abstract}
A B S T R A C T
High-energy ball-milling is proven to be an effective technique for manufacturing reactive aluminum nanopowders. The procedure of milling presented in this work allows the elaboration of aluminum powders with specific surface areas around $20 \mathrm{~m}^{2} / \mathrm{g}$. The particles have platelet morphology and are constituted by a nanocrystalline aluminum core surrounded by a thick amorphous alumina layer of $4.5 \pm 0.5 \mathrm{~nm}$. The reactivity of the powders is enhanced as compared to nanopowders elaborated with techniques involving vapor phase condensation. The morphology, the microstructure and the initial thickness of the alumina layer are shown to be important parameters that influence the reactivity. The method could be extended to any other ductile metal, provided a hard surface layer is continuously formed during milling.
\end{abstract}

\section{Introduction}

Aluminum nanopowders (Al-NPs) are widely studied because of their applications as propellant rate modifiers, explosive additives and energetic microsystems [1,2]. In all those applications, it is the highly exothermic reaction of aluminum with an oxidant that confers to the powders their reactive and/or propulsive properties. Al-NPs can be defined as powders having specific surface areas higher than $10 \mathrm{~m}^{2} / \mathrm{g}$. Each particle is constituted by a crystalline aluminum core covered by a thin amorphous alumina layer [1]. For low heating rates, a diffusion controlled mechanism is generally proposed to explain the oxidation mechanisms of AlNPs. In that case, the oxidation of aluminum is stepwise and linked to the polymorphic transitions of the alumina shell [3]. The first oxidation step (around $550{ }^{\circ} \mathrm{C}$ ), is related to the crystallization of the native amorphous layer into $\gamma$-alumina. The density increase of alumina upon crystallization leads to the breakage of the layer and the new as-formed bare aluminum zones immediately oxidize, explaining the increase of the oxidation rate. Because the reactivity of aluminum powders depends both on specific surface area and microstructural changes, it is interesting to test several elaboration methods in order to optimize both parameters. Until now, AL-NPs are manufactured either by vapor phase condensation or by liquid state chemistry [1]. In this paper a mechanical milling approach is proposed for the synthesis of highly reactive Al-NPs. Milling techniques are currently experiencing a revival for

\footnotetext{
* Corresponding author. Tel: +33 413551819.

E-mail address: renaud.denoyel@univ-amu.fr (R. Denoyel).
}

the manufacturing of nanostructured powders with enhanced properties as compared to their bulk counterpart [4,5] but to our knowledge, they were up to now never used to optimize the reactivity of aluminum powders. Indeed, due to their ductility, it is very difficult to increase specific surface area higher than $16 \mathrm{~m}^{2} \mathrm{~g}^{-1}$ by this method [6]. In this contribution, we show that, thanks to a milling procedure in which air is introduced in a controlled way, it is possible to increase the specific surface area of the powders and to modify the microstructure of the aluminum particles.

\section{Experimental details}

Aluminum powder from Alfa Aesar (purity=99.8\%) was used as the starting material. The milling was conducted with a highenergy planetary ball mill (P4 Fristch) using vials and balls in stainless steel in order to limit the amount of impurities [7,8]. The rotation speed of vials and plateau were respectively fixed to $800 \mathrm{rpm}$ and $400 \mathrm{rpm}$, in opposite directions. Paraffin oil was added into the vials in order to minimize cold welding and to increase the efficiency of the milling [9]. For all samples, the total milling time was fixed to $16 \mathrm{~h}$ by alternating $10 \mathrm{~min}$ of milling and $30 \mathrm{~min}$ of rest in order to reduce the temperature increase inside the vials. A controlled quantity of air $\left(71 \mathrm{~cm}^{3}\right)$ was added once (MM-air-1), four times (MM-air-4), eight times (MM-air-8) and 16 times (MM-air-16). The first filling was done at the beginning of the milling; the others were done at equal time periods of milling, i.e. every $4 \mathrm{~h}$, every $2 \mathrm{~h}$ and every hour for MM-air-4, MM-air-8 and MM-air-16, respectively. At the end of the procedure, the paraffin oil was removed as described in [10]. The purity of the 
powders was checked by ICP analyses. In the following, these samples will be compared to other powders having a spherical morphology: a micronic powder from Hermillon poudres@ (Micro$\mathrm{H})$, two nanopowders elaborated by wire electro explosion (WEE) and passivated either in air atmosphere (Nano-G) or in a liquid solution containing stearic acid (Nano-L) (see [11] for details).

Nitrogen adsorption-desorption isotherms were determined at $77 \mathrm{~K}$ using a commercial Autosorb-1 apparatus from Quantachrome.

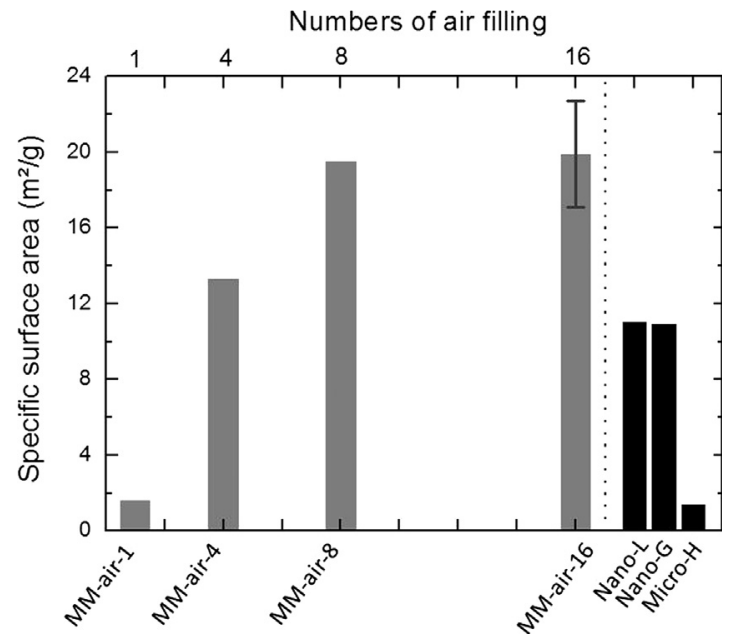

Fig. 1. Specific surface area of the powders plotted as a function of the number of air introduction. The results are compared to spherical powders obtained by other elaboration processes.
Transmission electron micrographs were taken by an FEI Titan 80-300 transmission electron microscope equipped with an image corrector and working at an acceleration voltage equal to $300 \mathrm{kV}$. Standard TEM imaging was performed and, in order to suppress the contrast variations due to changes in crystallographic orientations, images were also taken in the STEM mode (STEM-HAADF). High resolution thermogravimetry measurements (HRTGA) were carried out under a dynamic dry air atmosphere $(60 \mathrm{ml} / \mathrm{min})$ with a TG Q-Serie 500 from TA-Instrument.

\section{Results and discussion}

The adsorption-desorption isotherms are characteristic for a non-porous material and the BET equation was used to calculate the specific surface areas $a_{s}$. As presented in Fig. 1, milling without air renewal (MM-air-1) leads to powders with low specific surface area typical of micron-sized particles and comparable to the Micro-H powder. As soon as air is introduced during the milling the specific surface area increases to values higher than $10 \mathrm{~m}^{2} / \mathrm{g}$. After eight air fillings, the specific surface area obtained is around $20 \mathrm{~m}^{2} / \mathrm{g}$ which is much higher than the ones obtained for WEE powders [12]. Milling is thus an effective technique to synthesize Al-NPs. TEM image of Fig. 2a shows the platelet morphology of the particles, as expected from the ductility of aluminum and in agreement with previous studies $[5,10]$. The particles appear themselves as aggregates of smaller particles with poorly defined shapes and dimensions smaller than $100 \mathrm{~nm}$ as seen on the STEMHAADF image (Fig. 2b). The particles are made of polycrystalline Al (Fig. 2c) surrounded by an amorphous layer with a thickness of $4.5 \pm 0.5 \mathrm{~nm}$ (Fig. 2d). Amorphous alumina at the grain boundaries
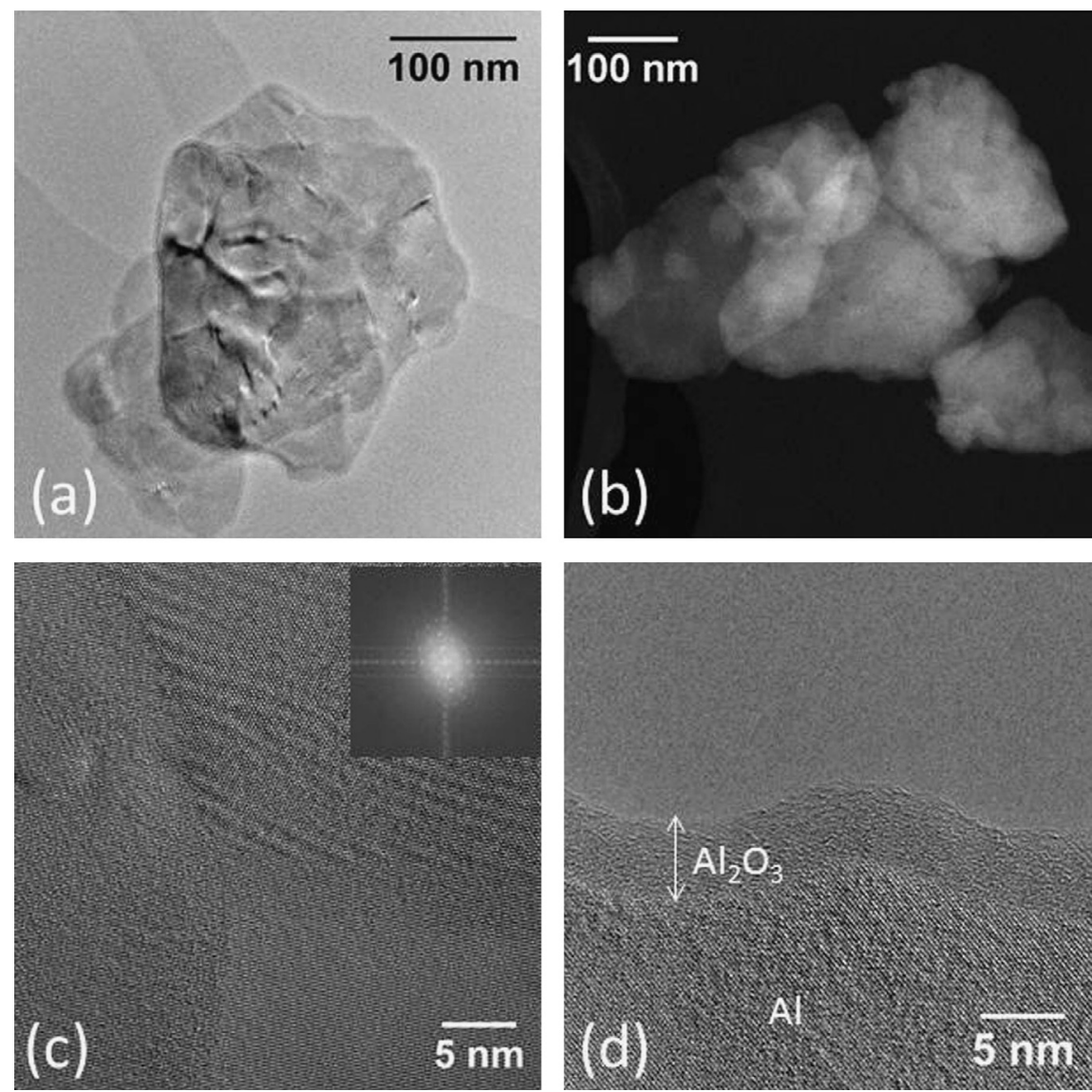

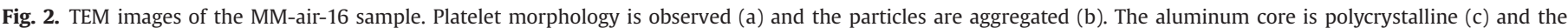
amorphous alumina layer has a thickness around $4.5 \pm 0.5 \mathrm{~nm}$ (d). 


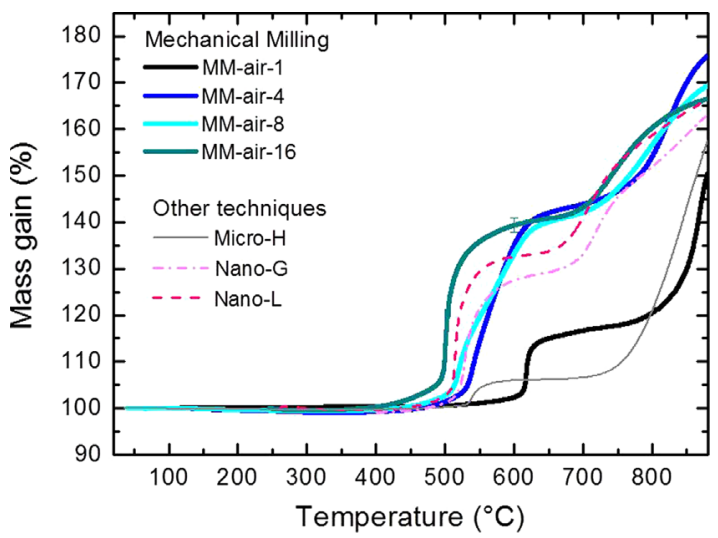

Fig. 3. High resolution thermo-gravimetric analyses of the powders obtained by mechanical milling and compared to other elaboration processes.

could not be evidenced (Fig. 2c). Interestingly, the thickness of the surrounding alumina layer is larger than the commonly reported value of $3 \pm 0.5 \mathrm{~nm}$ for Al-NPs synthesized using other techniques $[1,13,14]$ and it may be a consequence of the introduction of air during the milling.

Fig. 3 shows the HRTGA curves obtained for the milled powders and compared with other aluminum powders. The expected $[1,3,10,13]$ stepwise oxidation is systematically observed for all the powders. Two values can be used to quantify and compare the reactivity of different powders: (i) the temperature $T_{1}$ at which the oxidation starts (defined as the inflexion point of the first step on the curve) and (ii) the mass gain after the first oxidation step $M_{1}$. A powder with enhanced reactivity will be thus characterized by a lower $T_{1}$ and a higher $M_{1}$ as compared to the existing ones. As seen in Fig. 3, the temperature $T_{1}$ is continuously lowered by the addition of air during milling and reaches a value around $500{ }^{\circ} \mathrm{C}$ for the MM-air-16 powder. Moreover, milling under air leads to a stationary value of $M_{1}$ around $40 \%$ which is much higher than anyone obtained for the WEE powders. Finally, the platelet morphology seems advantageous for the mass gain: for micronsized powders (MM-air-1 compared to Micro-H), the mass gain $M_{1}$ is higher for platelets than for spherical particles. The continuous decrease of $T_{1}$ with increasing the quantity of air during the milling can be explained by the formation, during the milling, of a thicker amorphous layer that reaches a value equal to $4.5 \pm 0.5 \mathrm{~nm}$ for MMair-16 sample (Fig.2d). Under oxidizing conditions, this layer reaches a critical value for crystallization at a lower temperature and the first oxidation step is advanced. This effect is probably enhanced by the polycrystalline nature of the aluminum core (Fig. 2c), since the critical thickness is dependent on the crystallographic orientation of the aluminum crystallites [15]. The decrease of $T_{1}$ could also be linked to the microstructure of the metallic core since grain boundary distribution is known to modify the properties of metals [16]. In the present study, it may increase the speed of diffusion species through the aluminum core. In the same way, the total mass increase at $880{ }^{\circ} \mathrm{C}$ diminishes with the quantity of air introduced which is also related to the introduction of air during the milling that increases the quantity of alumina in disfavor to the total amount of metallic aluminum in the powder. This is a general result with Al-NPs: the higher the specific surface area the lower is the metallic content due to the existence of the alumina layer. For energetic applications, a compromise between reactivity (higher surface area) and energy release during combustion (high aluminum content) has to be found.

\section{Conclusion}

In summary we have proved that high-energy ball milling is an effective technique to synthesize reactive Al-NPs. The introduction of air during milling enables to obtain powders with high specific areas: the continuous regeneration of the alumina layer maintains the hardness of the powders which in turn can be more easily broken. The morphology and the microstructure of the aluminum core and the alumina shell are shown to be key parameters that directly influence the reactivity. High-energy ball milling could be used to tune the properties of the elaborated powders according to the desired mass increase or advanced oxidation. At last, the method could be extended to any other ductile metal, provided a hard surface layer is continuously formed during milling.

\section{Acknowledgment}

M. Dumont and J. Rogez (IM2NP) are acknowledged for fruitful discussions. TEM measurements were performed on the CIMPACA platform. SNPE is thanked for providing plasma and WEE samples. This work was granted by Institut Carnot STAR and C'Nano PACA.

\section{References}

[1] Dreizin EL. Progress in Energy and Combustion Science 2009;35:141-67.

[2] Rossi C, Esteve D. Sensors and Actuators A 2005;120:297-310.

[3] Trunov MA, Schoenitz M, Zhu X, Dreizin EL. Combustion and Flame 2005; 140: 310-8.

[4] Patro LN, Hariharan K. Materials Letters 2012;80:26-8.

[5] Hong S, Kim BK. Materials Letters 2001;51:139-43.

[6] Hong SH, Lee DW, Kim BK. Journal of Materials Processing Technology 2000;100:105-9.

[7] Eckert J, Holzer JC, Ahn CC, Fu Z, Johnson WL. Nanostructured Materials 1993:2:407-13.

[8] Revesz A. Journal of Materials Science 2005;40:1643-6.

[9] Suryanarayana C. Progress in Materials Science 2001;46:1-184.

[10] André B, Coulet MV, Dumont M, Rogez J, Heresanu V, Rufino B, et al International Journal of Nanotechnology 2012;9:618-29.

[11] Rufino B, Coulet MV, Bouchet R, Isnard O, Denoyel R. Acta Materialia 2010;58:4224-32.

[12] Kwon YS, Gromov AA, Ilyin AP, Rim GH. Applied Surface Science 2003;211: 57-67.

[13] Rufino B, Coulet MV, Boulch F, Lacroix G, Denoyel R. Acta Materialia 2007;55: $2815-27$.

[14] Firmansyah DA, Sullivan K, Lee KS, Kim YH, Zahaf R, Zachariah MR, et al. Journal of Physical Chemistry C 2012;116:404-11.

[15] Jeurgens LPH, Sloof WG, Tichelaar FD, Mittemeijer EJ. Physical Review B 2000;62:4707-19.

[16] Kobayashi S, Tsurekawa S, Wanatabe T, Palumbo G. Scripta Materialia 2010;62: 294-7. 